\title{
Atypical Eating Behaviors Identified in Children with Fetal Alcohol Spectrum Disorders, Aged 3 to 5 Years, Using the Children's Eating Behavior Questionnaire in a Caregiver-Reported Online Survey
}

\author{
Shirley F. Evans ${ }^{1, *}$, Mark Payton ${ }^{2}$ and Tay Kennedy ${ }^{1}$ \\ ${ }^{1}$ Department of Nutritional Sciences, College of Human Sciences, Oklahoma State University, 301 Human \\ Sciences, Stillwater, OK 74078, USA \\ ${ }^{2}$ Department of Statistics, College of Arts and Sciences, Oklahoma State University, 301 MSCS (Math \\ Statistics and Computer Sciences), Stillwater, OK 74078, USA
}

\begin{abstract}
Background: Children with fetal alcohol spectrum disorders (FASDs), aged 3 to 5 years, have physical, behavioral, and functional problems. Because of alcohol-related deficits, children with FASDs are at risk for malnutrition; yet, little is known about how FASD affects eating behavior and nutrition.

Aim: The purpose of this study was to identify atypical eating behavior in children with FASDs, aged 3 to 5 years, and their associations with socio-demographic characteristics.

Method: This descriptive cross-sectional study gathered data from a caregiver-reported online survey targeting the eating behavior of preschool-aged children with FASDs. The survey included the Children's Eating Behavior Questionnaire (CEBQ) and a socio-demographic questionnaire.

Participants/Setting: Seventy-four caregivers qualified for the study with nine having two children with FASDs. Responses to survey questions varied since caregivers had permission to omit any question.

Results: Significant differences were found between the preschool-aged children with FASDs and Wardle's published normative sample by gender and age. Compared to reported norms, study children scored higher in Desire to Drink, Food Responsiveness, Emotional Overeating, and Food Fussiness, and lower in Enjoyment of Food. Regarding sociodemographic characteristics, there was greater Enjoyment of Food with larger families and Food Avoidance with collegeeducated caregivers.

Conclusion: Children with FASDs, aged 3 to 5 years, have atypical eating behaviors characteristic of maladaptive appetites, overeating under stress, selective eating, slowness in eating, and an excessive need for drinks, in comparison with a published normative sample.
\end{abstract}

Keywords: Fetal alcohol syndrome, prenatal alcohol exposure, atypical eating behavior, preschool-aged children, and Children's Eating Behavior Questionnaire.

\section{INTRODUCTION}

Children with fetal alcohol spectrum disorders (FASDs) face a lifetime of difficulties from various problems secondary to prenatal alcohol exposure [1]. Since alcohol is a neurobehavioral teratogen, it has been proposed the array of the effects in FASD may be from altered epigenetic mechanisms [2]. The effects can present as physical, neurological, and/or behavioral abnormalities, depending on the timing, frequency, and quantity of maternal alcohol intake during gestation [3, 4]. Due to the alcohol-related injuries, children with FASDs are at increased risk for nutrition and eating problems [5].

Fetal alcohol syndrome (FAS), recognized as one of the foremost causes of preventable intellectual

*Address correspondence to this author at the Department of Nutritional Sciences, Oklahoma State University, 301 Human Sciences, Stillwater OK 74078, USA; Tel: 405-744-3808; Fax: 405-744-1357;

E-mail: shirley.evans@okstate.edu disability in the United States (U.S.), is the severest condition from prenatal alcohol exposure [6, 7]. Although not a diagnostic term, fetal alcohol spectrum disorders (FASDs), which includes FAS, represent the entire range of permanent disabilities occurring from maternal alcohol consumption [8]. FASD has a prevalence of approximately 10 cases per 1,000 live births in the U.S., which is higher than rates of Down's syndrome (1 per 1,000 live births) and Spina Bifida (1 to 2 per 10,000 live births) [9-11].

Even though growth deficiency and low birthweight are common in FAS, studies have shown overweight and obesity in children with FASDs, suggestive of a dichotomy in eating difficulties [12-14]. While eating problems can occur in children with normal development, children with neurological, physical, or behavioral impairments are more prone to have persistent challenges in nutrition and eating leading to nutrient deficiency and weight issues [15]. Recent 
studies have described irregularities in the nutrition and eating behaviors of children with FASDs, such as dietary deficiencies, poor appetite, excessive dietary sugar, abnormal mastication, and selective eating [13]. In addition, many symptoms associated with FASD, such as abnormal gastrointestinal function, anomalies of the lip/palate, poor motor skills, and mental health disorders, can give rise to an inadequate nutritional intake [5, 16, 17]. Yet, only a few studies have specifically examined eating behaviors and weight in children with FASDs, particularly aged 3 to 5 years old $[13,18]$.

Since a child needs to eat properly to grow up, learn, and interact socially with others, it is important to define abnormal eating behaviors in children to ensure adequate nutrition and proper weight [19]. Assessment instruments, such as the Children's Eating Behavior Questionnaire (CEBQ), are available to characterize atypical eating behaviors in young children [20-22]. Many studies have used caregiver-reported questionnaires as a method of data collection regarding children [23, 24]. Caregivers, who are the primary caretakers, can provide invaluable first-hand insight on the specific eating behaviors encountered in children with FASDs, aged 3 to 5 years [13].

The hypothesis of the study was that caregivers would report atypical eating behavior in children with FASDs, aged 3 to 5 years. The aim was to describe eating problems in children with FASDs at an age when the child becomes an independent eater (aged 3 to 5 years) and nutrition is critical in brain development [19, 25]. This is particularly important since neurological impairments are predominant adverse outcomes in FASD [3, 26].

This research was part of the project, Eating Behavior in Children with FASDs: A Mixed Methods Study, which investigated the eating behavior of children with FASDs, aged 3 to 5 years, using an online survey of FASD caregivers and focus groups of professionals in FASD pediatric healthcare. The goal of the study was to identify atypical eating behaviors for development of future nutrition interventions to reduce the adverse effects of FASD on childhood nutrition, growth, and function.

\section{METHODS}

\section{Research Design and Participants}

This descriptive study consisted of a cross-sectional online survey for caregivers of children with FASDs, aged 3 to 5 years, which did not entail a post survey follow-up or provision of incentives. Through convenience sampling, recruitment of caregivers began on August 8, 2013 and ended on January 20, 2015. Caregivers were recruited through electronic communications with attached invitation flyers, which were sent to FASD websites (e.g., National Organization on FAS, 2012), government organizations, healthcare professionals, child study centers, and adoption agencies. An additional approach in participant recruitment was through snowball sampling with survey respondents and contacts asked to refer the survey to other caregivers of children with FASDs, aged 3 to 5 years. For this study, the term, caregivers, represented adults providing primary care at home to children with FASDs. Participants met inclusion criteria by responding to forced-answer questions that they were at least 18 years of age and had at least one child with FASD, aged 3 to 5 years. Male or female caregivers of the children included, but were not limited to, biological, adoptive, or foster parents, and relatives. The survey accommodated caregivers having up to four children with FASDs.

The data collection for the study was through Qualtrics software (Qualtrics@ 2015, Provo, UT). Since the survey did not collect identifying information, the Oklahoma State University Institutional Review Board approved the study with an exemption for the signature requirement. Upon answering the qualification questions correctly and acknowledging consent on the survey cover page, respondents were permitted access to the survey link.

\section{Survey Response Rate and Sample Size}

Of the 290 viewing the survey cover page, 143 $(49 \%)$ were caregivers of children with FASDs. From the 143 caregivers, there were 74 caregivers $(51 \%)$, who qualified for the study by having at least one child with an FASD, aged 3 to 5 years. Nine $(12 \%)$ of the caregivers had a second child in the target age range. In this study, caregivers had the choice of stopping at any time or omitting questions during the survey; hence, sample sizes of questionnaire items vary (sample sizes are indicated in tables). Due to this, caregiver data from the socio-demographic questionnaire varied from $49(66 \%)$ to $74(100 \%)$ responses. The data on the children's sociodemographics and CEBQ items ranged from 63 (79\%) to $80(100 \%)$ of responses. Three of the second children with FASDs were without reported data. 


\section{Data Collection and Measurement}

In the larger study, the online caregiver-reported survey consisted of socio-demographic questions, children anthropometric measurements, and two validated questionnaires, the Children's Eating Behavior Questionnaire (CEBQ), which assesses eating styles of children, and the Child Behavior Checklist (CBCL), which evaluates behavioral problems in children [20,27,28]. This study included the $C E B Q$, the socio-demographic questionnaire, and caregiver-reported anthropometric measurements of the children.

\section{Socio-Demographic Questionnaire}

The socio-demographic questions, drawn from U.S. 2010 population census, were established after consultation with a statistician [29]. This questionnaire requested information, such as age, sex, and ethnicity, about the caregivers and children with FASDs.

\section{Children Anthropometric Measurements}

Anthropometrics for the children with FASDs were caregiver-reported measurements, which included the children's birth weight, current weight, and current height. Anthropometric measurements of children through maternal, parent or caregiver-reported surveys have been evaluated in other published studies and found to be appropriate for birthweight and in weight for length percentiles when outliers were removed [30, 31]. Birthweight was categorized as a low birthweight of $<2.5 \mathrm{~kg}$. Body mass index (BMI) was calculated as weight in kilograms divided by the square of the height in meters $\left(\mathrm{kg} / \mathrm{m}^{2}\right)$. After adjusting for age and sex, $\mathrm{z}-$ scores and percentiles were determined for weight, height, and BMI, using the online CDC software tool, Epi Info $7^{\text {TM }} 7.1 .5$ (March 15, 2015, Atlanta, GA), and based on the reference data from U.S. 2000 CDC growth charts [32]. BMI percentiles were categorized as underweight $\left(\mathrm{BMI}<5^{\text {th }}\right.$ percentile), normal weight $\left(B M I \geq 5^{\text {th }}\right.$ percentile to $<85^{\text {th }}$ percentile), and overweight/obese $\left(\mathrm{BMI} \geq 85^{\text {th }}\right.$ percentile to $100^{\text {th }}$ percentile) [33]. Children with BMI percentiles in the overweight and obese categories were grouped together as a 'not normal' category due to small sample sizes.

\section{Children's Eating Behavior Questionnaire}

The CEBQ, a parent/caregiver-reported measure, consists of eight subscales (35 items) and has documented internal validity with good test-retest reliability [20]. This questionnaire can be completed by respondents in approximately 15 minutes or less and has a response format of a 5-point Likert-type scale. The rating of each subscale item is never (1), rarely (2), sometimes (3), often (4), and always (5).

The $C E B Q$ provides assessment in the following subscales: Food Responsiveness (FR, eating in response to environmental cues, 5 items), Enjoyment of Food (EF, desire to eat, 4 items), Desire to Drink (DD, desire to carry around a sugar-sweetened drink, 3 items), Satiety Responsiveness (SR, regulating a decrease in food intake after eating, 5 items), Food Fussiness (FF, selective dietary choices with rejection of unfamiliar foods, 6 items), Emotional Overeating (EOE, increased eating during stress, 4 items), Emotional Undereating (EUE, decreased eating during stress, 4 items), and Slowness in Eating (SE, a meal lasting over 30 minutes from a lack of food enjoyment resulting in decreased food intake, 4 items) [20]. Examples of subscale items are as follows: My child's always asking for food (FR), My child enjoys eating $(\mathrm{EF})$, If given the chance, my child would always be having a drink (DD), My child gets full up easily (SR), My child enjoys tasting new foods (FF), My child eats more when anxious (EOE), My child eats less when s/he is upset (EUE), and My child finishes his/her meal quickly (SE). The following subscale items underwent reverse coding: My child has a big appetite (SR), My child enjoys tasting new foods (FF), My child enjoys a wide variety of foods (FF), My child is interested in tasting food s/he hasn't tasted before (FF), and My child finishes his/her meal quickly (SE).

For this study, Cronbach's alpha was determined for each CEBQ subscale and ranged from 0.79 to 0.94 . In the Wardle et al. sample of 320 parents from eight primary school nursery classes and nursery schools (urban and suburban), the Cronbach's alphas ranged from 0.74 to 0.90 [20]. The study's CEBQ internal consistency appeared acceptable to high for all subscales and comparable to Wardle et al. (2001).

When developing the CEBQ, the subscales of Satiety Responsiveness and Slowness in Eating had similar factor loading in Principal Component Analysis (PCA) resulting in seven instead eight subscales [20]. However, the eight subscales were maintained in the CEBQ to yield a better description of the eating behaviors. Likewise, PCA in this study extracted 7 components out of the 35 CEBQ items as subscales with eigenvalues greater than one that explained $42 \%$ to $80 \%$ of the variance. Following Wardle et al., the study analyses also maintained eight subscales. 
This study used a normative sample (samples 2 and 3 combined) for comparison from the Wardle et al. study [20]. From eight nursery school and primary school nursery classes, sample 2 had 100 boys and 78 girls with a mean age of $4.2 \pm 1.4$ years. In sample 3 , there were 111 boys and 97 girls with a mean age of $5.6 \pm 1.5$ years recruited from six nursery schools and advertisement [20]. The caregivers of the children in the normative sample were from a broad range of socio-demographic backgrounds.

The CEBQ identifies different dimensions in a child's eating behavior as described by parents or caregivers [20]. Many studies have utilized the CEBQ to examine eating and weight status in children [34-36]. It has also been employed in assessment of other conditions, such as eating problems in young children with dental caries [23]. The subscales, when grouped together, represent indicators that stimulate food intake (Food Approach) or inhibit food intake (Food Avoidance) [20]. Higher subscale scores of Food Approach (EF, FR, EOE, and DD) depict an increased response to food intake, which could lead to overweight/obesity [20]. Higher subscales scores of Food Avoidance (SR, SE, FF, and EUE) typify food restraint with underweight tendencies.

\section{Statistical Analyses}

The IBM SPSS Version 21.0 software for Windows (SPSS, Inc., Chicago, IL) was used for data analyses. Descriptive statistics were conducted on all the first and second children of the caregivers and then repeated without the second child of the caregivers. With the results between the two groups being similar, analysis of the study considered all the children (child 1 and 2 of the caregiver) as one group. Missing responses were omitted from analyses and outliers were identified but not removed. Descriptive statistics summarized the socio-demographic profiles of caregivers and children with FASDs. Measurement of interval, nominal, ordinal, and Likert-type scale variables display the distribution and frequency of outcomes. Two-tailed two population $t$-tests for independent samples were conducted comparing the summary statistics from the Wardle et al. normative sample and the FASD data [20]. Cross tabulations were used to compare percentages of weight status between the children with FASDs to U.S. 2013 values, in which underweight and overweight groups were combined to represent 'not normal' percentages [37]. To identify atypical eating behaviors and associations, Pearson's correlations, independent samples $t$-tests, and analyses of variance were conducted. If indicated, post hoc pairwise comparisons with Tukey adjustments were performed. Z-scores of the study children's weight, height, and BMI were compared to the U.S. reference population $(M=0)$ with one sample $t$-tests [32]. Due to the study being exploratory and that the eating behavior in children with FASDs has not yet been fully described, familywise error was not controlled and the number of analyses erred on the side of minimizing type II error. Using Cohen's conventions, correlations were interpreted as small ( 0.1 to 0.3 ), medium ( 0.3 to 0.5 ), and large ( 0.5 to 1.0) [38]. Significance for analysis was set on a twotailed $P$ value $<0.05$.

\section{RESULTS}

\section{Descriptive Statistics of Socio-demographic Characteristics}

Descriptive statistics of the caregiver and children socio-demographic characteristics are in Tables 1 and 2, respectively. Most caregivers responding to the online survey were grandparents or adoptive/foster parents, who resided in the United States and had a mean age of $42.3 \pm 8.1$ years. The majority of the children's caregivers were college educated, unemployed/part-time employed, Caucasian, and females, who were married for the first time and lived in a household with 4 to 5 members. The children with FASDs had a mean age of $4.3 \pm 0.7$ years with a higher percentage of the children being male and Caucasian.

Table 1: Socio-demographic characteristics for the 74 caregivers who participated in the online survey evaluating the atypical eating behavior of children with fetal alcohol spectrum disorders, aged 3 to 5 years ${ }^{a}$

\begin{tabular}{|l|c|}
\hline Socio-demographic Characteristics & $\boldsymbol{n}(\%)$ \\
\hline \hline Sex & \\
\hline Male & $1(2)$ \\
\hline Female & $50(98)$ \\
\hline Relationship to child & \\
\hline Biological parent & $1(1)$ \\
\hline Adoptive parent or Foster parent & $63(85)$ \\
\hline Grandparent & $9(12)$ \\
\hline Other & $1(2)$ \\
\hline Ethnicity & \\
\hline African American & $1(2)$ \\
\hline Asian & $2(4)$ \\
\hline Hispanic & $1(2)$ \\
\hline Caucasian & $46(90)$ \\
\hline Native American including Alaskan Native & $1(2)$ \\
\hline
\end{tabular}


(Table 1). Continued.

\begin{tabular}{|c|c|}
\hline Marital status & \\
\hline Single: never married, divorced, and widowed & $9(18)$ \\
\hline Married: first time & $31(61)$ \\
\hline Remarried & $11(21)$ \\
\hline \multicolumn{2}{|l|}{ Number of members per household } \\
\hline 2 and 3 members & $13(26)$ \\
\hline 4 and 5 members & $21(43)$ \\
\hline 6,7, and 8 members & $15(31)$ \\
\hline \multicolumn{2}{|l|}{ Education } \\
\hline $\begin{array}{l}\text { 11th or12th grade, Some Vo-tech or College } \\
\text { classes, or Vo-tech graduate }\end{array}$ & $16(32)$ \\
\hline College graduate & $23(46)$ \\
\hline Postgraduate degree & $11(22)$ \\
\hline \multicolumn{2}{|l|}{ Employment status } \\
\hline $\begin{array}{l}\text { Unemployed, Not employed (disability), Retired, } \\
\text { and Unknown }\end{array}$ & $23(46)$ \\
\hline Employed Part-time & $14(28)$ \\
\hline Employed Full-time & $13(26)$ \\
\hline \multicolumn{2}{|l|}{ Total 2012 family income } \\
\hline Unknown & $1(2)$ \\
\hline Under $\$ 30,000$ & $8(16)$ \\
\hline$\$ 31,000$ to $\$ 75,000$ & $20(40)$ \\
\hline Greater than $\$ 75,000$ & $21(42)$ \\
\hline \multicolumn{2}{|l|}{ Residence } \\
\hline \multicolumn{2}{|l|}{ United States } \\
\hline North-east region & $6(12)$ \\
\hline \multicolumn{2}{|l|}{ New Jersey, New York, Pennsylvania } \\
\hline Midwest region & $14(29)$ \\
\hline \multicolumn{2}{|l|}{ Illinois, Indiana, Michigan, Minnesota, Wisconsin } \\
\hline West region & $13(26)$ \\
\hline \multicolumn{2}{|l|}{ Alaska, Arizona, California, Colorado, Washington } \\
\hline South region & $14(29)$ \\
\hline \multicolumn{2}{|l|}{$\begin{array}{l}\text { Arkansas, Florida, Maryland, North Carolina, } \\
\text { Texas }\end{array}$} \\
\hline International & $2(4)$ \\
\hline Canada, Scotland & \\
\hline
\end{tabular}

${ }^{a}$ Sample sizes vary since caregivers were given the option to omit any question if so desired.

\section{Descriptive Statistics of Children Anthropometric Measurements}

Table 2 also includes caregiver-reported anthropometric measurements of the children with FASDs, aged 3 to 5 years. The average birth was $2.7 \pm 0.7 \mathrm{~kg}$, with $60 \%$ of the children in the low birthweight category (birth weight $<2.5 \mathrm{~kg}$ ).
Table 2: Socio-demographic characteristics for the $\mathbf{8 0}$ children with fetal alcohol spectrum disorders, aged 3 to 5 years old, as reported by the caregivers in the online survey evaluating the children's atypical eating behavior ${ }^{a}$

\begin{tabular}{|c|c|}
\hline Socio-demographic characteristics & Total \\
\hline Birthweight (kg) & $M \pm S D^{\mathrm{b}}$ \\
\hline All children & $2.7 \pm 0.7$ \\
\hline Boys & $2.8 \pm 0.7$ \\
\hline Girls & $2.6 \pm 0.6$ \\
\hline Birthweight $\geq 2.5 \mathrm{~kg}$ & $n(\%)$ \\
\hline All children & $16(40)$ \\
\hline Boys & $9(56)$ \\
\hline Girls & $7(44)$ \\
\hline Birthweight $<2.5 \mathrm{~kg}$ & $n(\%)$ \\
\hline All children & $24(60)$ \\
\hline Boys & $15(63)$ \\
\hline Girls & $9(37)$ \\
\hline Z-scores: All children and by gender & $M \pm S D^{\mathrm{b}}$ \\
\hline \multicolumn{2}{|l|}{ Weight-for-age z-score } \\
\hline All children & $0.28 \pm 1.1$ \\
\hline Boys & $0.24 \pm 1.3$ \\
\hline Girls & $0.36 \pm 0.7$ \\
\hline \multicolumn{2}{|l|}{ Height-for-age z-score } \\
\hline All children & $0.10 \pm 2.0$ \\
\hline Boys & $-0.25 \pm 2.2$ \\
\hline Girls & $0.80 \pm 1.3$ \\
\hline \multicolumn{2}{|l|}{ Body mass index z-score } \\
\hline All children & $0.22 \pm 1.9$ \\
\hline Boys & $0.39 \pm 2.1$ \\
\hline Girls & $-0.10 \pm 1.2$ \\
\hline Sex & $n(\%)$ \\
\hline Boys & $49(61)$ \\
\hline Girls & $31(39)$ \\
\hline Age groups & $n(\%)$ \\
\hline 3-year-olds & $14(18)$ \\
\hline 4-year-olds & $30(37)$ \\
\hline 5-year-olds & $36(45)$ \\
\hline Ethnicity & $n(\%)$ \\
\hline African American & $9(15)$ \\
\hline Asian & $2(3)$ \\
\hline Hispanic & $8(13)$ \\
\hline Caucasian & $35(57)$ \\
\hline Native American, including Alaskan Native & $5(8)$ \\
\hline Other race & $3(4)$ \\
\hline
\end{tabular}


(Table 2). Continued.

\begin{tabular}{|c|c|}
\hline Body mass index percentile groups & $n(\%)$ \\
\hline Underweight (Body mass index $<5^{\text {th }}$ percentile) ${ }^{c}$ & $6(16)$ \\
\hline Boys & $5(83)$ \\
\hline Girls & $1(17)$ \\
\hline $\begin{array}{l}\text { Normal weight (Body mass index } \geq 5^{\text {th }} \text { percentile } \\
\text { to }<85^{\text {th }} \text { percentile) }\end{array}$ & $21(57)$ \\
\hline Boys & $11(52)$ \\
\hline Girls & $10(48)$ \\
\hline $\begin{array}{l}\text { Overweight/obese ('Not Normal group', Body } \\
\text { mass index } \geq 85^{\text {th }} \text { percentile to } 100^{\text {th }} \text { percentile) }\end{array}$ & $10(27)$ \\
\hline Boys & $8(80)$ \\
\hline Girls & $2(20)$ \\
\hline
\end{tabular}

${ }^{a}$ Sample sizes vary since the caregivers were given the option to omit any question if so desired.

${ }^{\mathrm{b}} M \pm S D=$ mean \pm standard deviation

${ }^{c}$ Mei Z, et al. Validity of body mass index compared with other bodycomposition screening indexes for the assessment of body fatness in children and adolescents. Am J Clin Nutr 2002; 75(6): 978-85.

\section{Descriptive Statistics of CEBQ Subscales}

In Tables $\mathbf{3}$ and $\mathbf{4}$, descriptive statistics of the CEBQ revealed the subscale, Desire to Drink, was the most commonly reported eating behavior problem for children with FASDs, aged 3 to 5 years. The most commonly reported subscales by age were Desire to Drink in 3-year-olds, Slowness in Eating in 4-year-olds and Food Fussiness in 5-year-olds. By sex, Food Fussiness and Slowness in Eating in boys and Desire to Drink in girls were also commonly reported subscales by the caregivers. Emotional Overeating was the least reported eating behavior overall, and by sex and age.

\section{Correlations between CEBQ Subscales}

Similar to the findings of Wardle et al., the Food Approach (EF, EOE, DD, and FR) and the Food Avoidance (SR, SE, FF, and EUE) subscales within each group were positively inter-correlated; while, between the two main scales, the subscales were negatively correlated [20]. Large statistically significant negative correlations were observed between two of the Food Approach and two of the Food Avoidance subscales (EF to SR, EF to FF, FR to SR, and FR to FF). Correlations are in Table 5.

Table 3: Descriptive statistics of the Children's Eating Behavior Questionnaire (CEBQ) subscales for the 80 children with fetal alcohol spectrum disorders ${ }^{a}$, aged 3 to 5 years, as reported by caregivers in the online survey evaluating the children's eating behavior, and independent samples $t$-tests by sex between the study children with fetal alcohol spectrum disorders and Wardle's published normative sample of children ${ }^{b}$ in the same age range

\begin{tabular}{|c|c|c|c|c|c|c|c|c|c|c|c|}
\hline \multirow[b]{2}{*}{$\begin{array}{c}\text { CEBQ } \\
\text { Subscales }\end{array}$} & \multicolumn{3}{|c|}{$\begin{array}{l}\text { All Children with Fetal } \\
\text { Alcohol Spectrum } \\
\text { Disorders }\end{array}$} & \multicolumn{2}{|c|}{$\begin{array}{l}\text { Boys with } \\
\text { Fetal Alcohol } \\
\text { Spectrum } \\
\text { Disorders }\end{array}$} & \multirow{2}{*}{$\begin{array}{c}\text { Boys of } \\
\begin{array}{c}\text { Normative } \\
\text { Sample }^{b} \\
(\mathrm{n}=215)\end{array} \\
M \pm S D^{\mathrm{c}}\end{array}$} & \multirow[b]{2}{*}{$\begin{array}{l}P \text { for } \\
t \text {-test }\end{array}$} & \multicolumn{2}{|c|}{$\begin{array}{c}\text { Girls with Fetal } \\
\text { Alcohol } \\
\text { Spectrum } \\
\text { Disorders }\end{array}$} & \multirow{2}{*}{$\begin{array}{c}\begin{array}{c}\text { Girls of } \\
\text { Normative } \\
\text { Sample }^{\mathrm{b}} \\
(\mathrm{n}=181)\end{array} \\
M \pm S D^{\mathrm{c}}\end{array}$} & \multirow[b]{2}{*}{$\begin{array}{l}P \text { for } \\
t \text {-test }\end{array}$} \\
\hline & $\begin{array}{c}\text { Cronbach's } \\
\alpha\end{array}$ & $M \pm S D^{c}$ & $n$ & $M \pm S D^{c}$ & $n$ & & & $M \pm S D^{c}$ & $n$ & & \\
\hline $\begin{array}{l}\text { Enjoyment of } \\
\text { Food }\end{array}$ & 0.94 & $3.2 \pm 1.1$ & 69 & $3.1 \pm 1.0$ & 45 & $3.6 \pm 0.8$ & 0.001 & $3.4 \pm 1.3$ & 24 & $3.6 \pm 0.9$ & 0.44 \\
\hline $\begin{array}{l}\text { Emotional } \\
\text { Overeating }\end{array}$ & 0.84 & $2.1 \pm 0.9$ & 68 & $2.2 \pm 1.0$ & 44 & $1.8 \pm 0.6$ & 0.02 & $2.1 \pm 0.9$ & 24 & $1.8 \pm 0.6$ & 0.11 \\
\hline $\begin{array}{l}\text { Desire to } \\
\text { Drink }\end{array}$ & 0.94 & $3.5 \pm 1.3$ & 69 & $3.5 \pm 1.3$ & 44 & $2.9 \pm 1.1$ & $<0.01$ & $3.5 \pm 1.3$ & 25 & $2.9 \pm 1.2$ & 0.03 \\
\hline $\begin{array}{l}\text { Food } \\
\text { Responsive- } \\
\text { ness }\end{array}$ & 0.93 & $2.8 \pm 1.3$ & 68 & $2.7 \pm 1.2$ & 44 & $2.3 \pm 0.8$ & 0.04 & $3.0 \pm 1.3$ & 24 & $2.2 \pm 0.8$ & $<0.01$ \\
\hline $\begin{array}{l}\text { Satiety } \\
\text { Responsive- } \\
\text { ness }\end{array}$ & 0.90 & $3.2 \pm 1.1$ & 69 & $3.2 \pm 1.0$ & 44 & $3.1 \pm 0.7$ & 0.59 & $3.2 \pm 1.2$ & 25 & $3.1 \pm 0.7$ & 0.83 \\
\hline $\begin{array}{l}\text { Slowness in } \\
\text { Eating }\end{array}$ & 0.92 & $3.4 \pm 1.2$ & 67 & $3.4 \pm 1.2$ & 44 & $3.1 \pm 0.8$ & 0.16 & $3.4 \pm 1.3$ & 23 & $3.2 \pm 0.8$ & 0.55 \\
\hline $\begin{array}{l}\text { Food } \\
\text { Fussiness }\end{array}$ & 0.90 & $3.3 \pm 1.1$ & 68 & $3.4 \pm 1.0$ & 43 & $3.1 \pm 0.9$ & 0.03 & $3.1 \pm 1.2$ & 25 & $2.9 \pm 0.9$ & 0.40 \\
\hline $\begin{array}{l}\text { Emotional } \\
\text { Undereating }\end{array}$ & 0.79 & $3.1 \pm 1.0$ & 63 & $3.2 \pm 1.0$ & 41 & $3.1 \pm 0.8$ & 0.60 & $3.0 \pm 1.0$ & 22 & $3.0 \pm 0.7$ & 0.96 \\
\hline
\end{tabular}

${ }^{\mathrm{a}}$ Sample sizes vary since the caregivers were given the option to omit any question if so desired

'Wardle J, et al. Development of the Children's Eating Behaviour Questionnaire. J Child Psychol Psyc 2001; 42(7): $963-970$.

${ }^{\mathrm{c}} M \pm S D=$ mean \pm standard deviation. 
Table 4: Descriptive statistics of the Children's Eating Behavior Questionnaire (CEBQ) subscales and independent $t$ tests by age between the children with fetal alcohol spectrum disorders ${ }^{\mathrm{a}}$, aged 3 to 5 years, as reported by caregivers in the online survey evaluating the children's eating behavior, and Wardle's published normative sample of children ${ }^{b}$ in the same age range

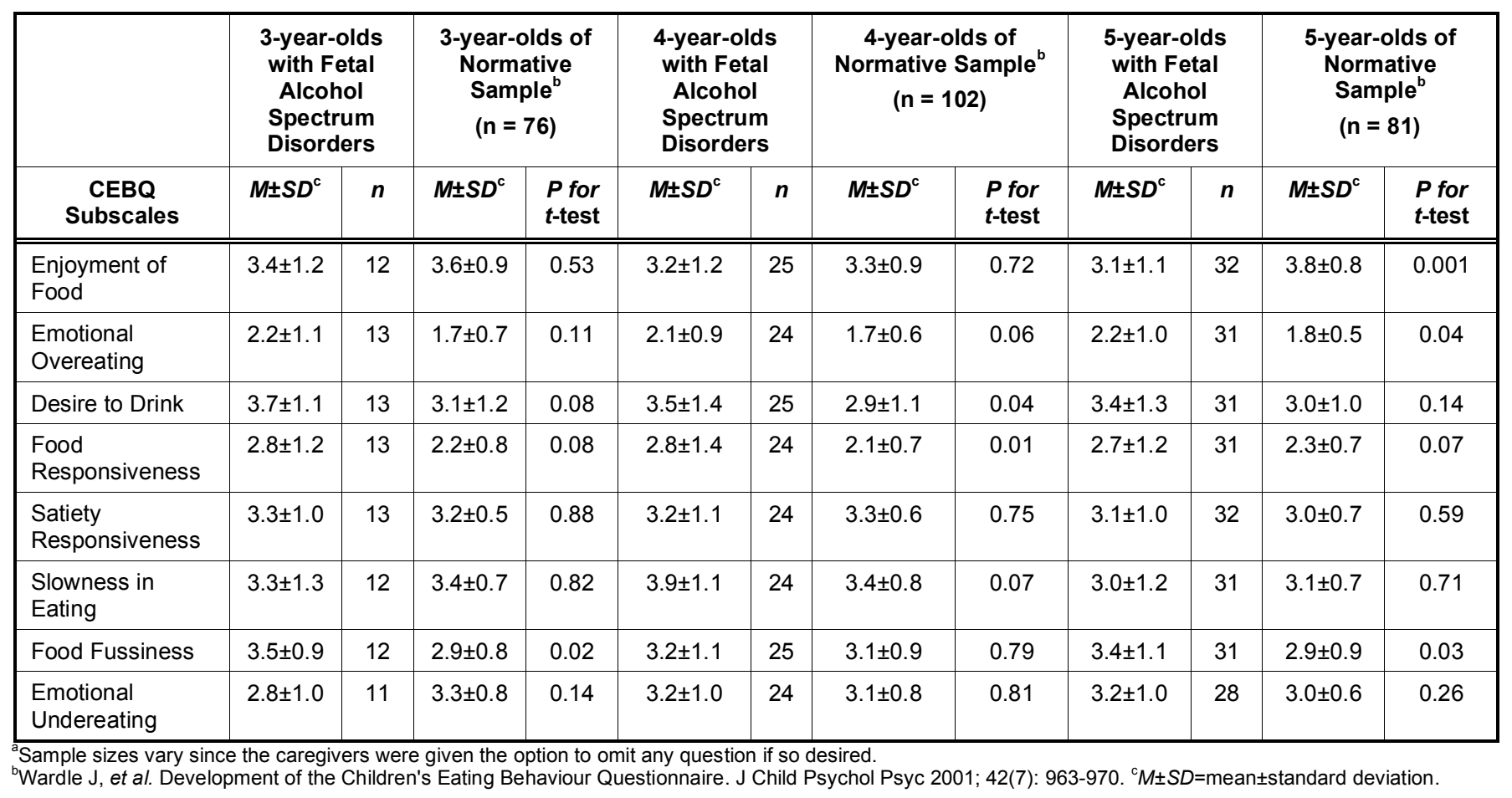

Table 5: Pearson's product-moment correlations between the Children's Eating Behavior Questionnaire (CEBQ) subscales, caregivers' number of household members, and birthweight of the children with fetal alcohol spectrum disorders ${ }^{a}$, aged 3 to 5 years, as reported by caregivers in the online survey evaluating the children's eating behavior

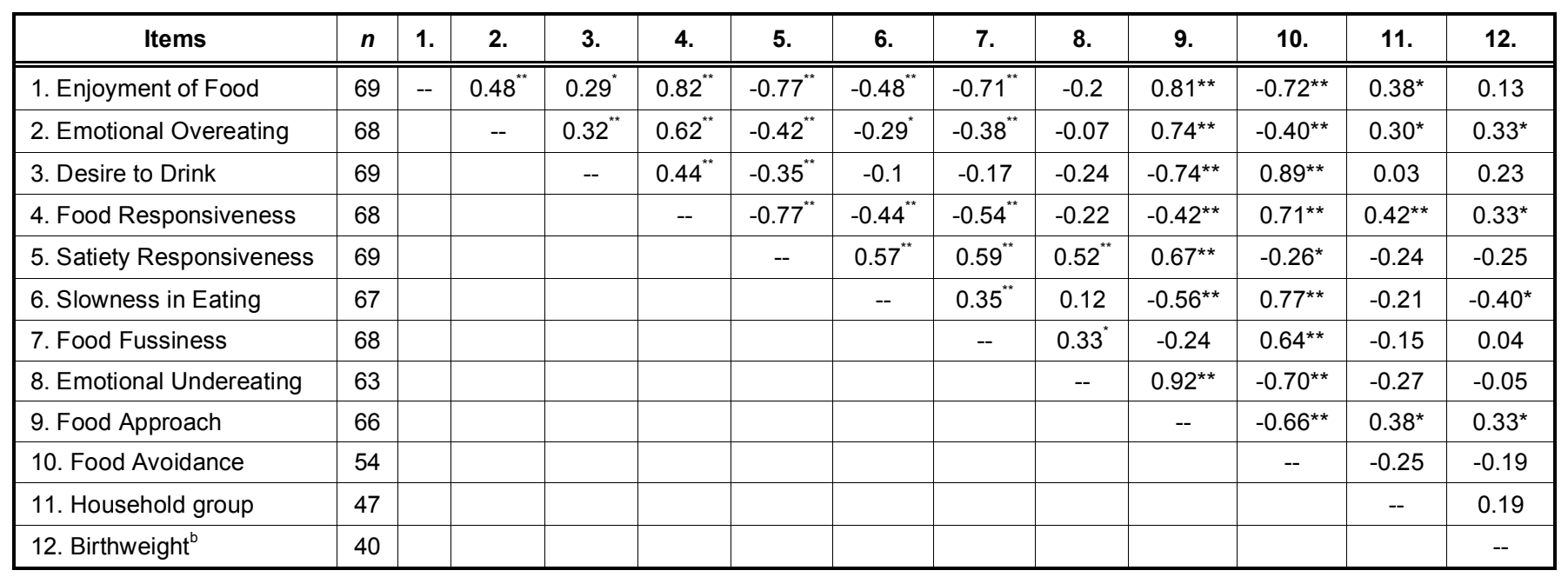

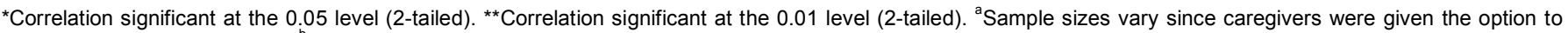
omit any question if so desired. ${ }^{\mathrm{b}}$ Birthweight of children in kilograms.

Relationships of CEBQ Subscales to the SocioDemographic Characteristics, Anthropometric Measurements, and Normative Sample

As reported in Table 6, caregiver income was higher with larger households $(r=0.34, P=0.02)$, higher education levels $(r=0.36, P=0.01)$, and being married $(r=0.28, P=0.05)$. Conversely, income level was lower with caregiver age $(r=-0.36, P=0.02)$. There were no associations with employment, child age, or ethnicity.

Study children $(M=3.4, S D=1.9, M=3.2, S D=0.9$, respectively) living in households of 6 to 8 members 
enjoyed food $[F(2,45)=3.97, P=0.02]$ and responded to food intake stimulators $[F(2,42)=2.33, P=0.03]$ more than the two and three member per household group $(M=2.1, S D=0.6, M=2.4, S D=0.6$, respectively). The four and five household member group $(M=2.5$, $S D=1.2, \quad M=2.7, \quad S D=0.8$, respectively) did not significantly differ from the other groups nor was there a statistically significant difference with Emotional Overeating between any groups. In overall eating styles $[F(2,37)=3.67, P=0.04]$, caregivers with a college degree $(M=3.8, S D=0.5)$ had children exhibiting higher Food Avoidance than children of caregivers with the high school/No Tech degree $(M=3.0, S D=0.9)$. There was no difference in children of caregivers with a postgraduate college degree $(M=3.3, S D=0.8)$. The eating behavior differences by sex and age were examined within the study children. There were no differences in the CEBQ subscales by sex. When evaluating age $[F(2,5)=4.53, P=0.02]$, there was significant relationship with age and Slowness in Eating in children. Post hoc comparisons (Tukey) found the 3year-olds were slower in eating than the 5-year-olds but there was no difference in the 4-year-olds. Means and standard deviations are in the descriptive analysis in Table 3.

Moreover, the CEBQ subscales, Food Responsiveness $\quad(r=0.33, \quad P=0.04), \quad$ Emotional Overeating ( $r=0.33, P=0.04)$, and Food Avoidance $(r=0.33, \quad P=0.04)$ were positively associated with birthweight; while there was an inverse correlation of higher birthweight and lower Slowness in Eating, which

Table 6: Pearson's product-moment correlations between socio-demographic characteristics of the caregivers and children with fetal alcohol spectrum disorders ${ }^{a}$, aged 3 to 5 years, as reported by the caregivers in the online survey evaluating the children's eating behavior

\begin{tabular}{|c|c|c|c|c|c|c|c|c|c|c|c|c|c|}
\hline & 1. & 2. & 3. & 4. & 5. & 6. & 7. & 8. & 9. & 10. & 11. & 12. & 13. \\
\hline 1. Age $(n=45)$ & -- & $-0.46^{* *}$ & 0.03 & 0.03 & $-0.36^{*}$ & -0.24 & 0.30 & 0.27 & -0.01 & 0.30 & 0.01 & 0.28 & 0.15 \\
\hline $\begin{array}{l}\text { 2. Household } \\
(n=49)\end{array}$ & & -- & -0.08 & -0.18 & $0.34^{*}$ & 0.22 & -0.22 & 0.02 & -0.03 & -0.05 & -0.12 & 0.08 & 0.19 \\
\hline $\begin{array}{l}\text { 3. Education } \\
(n=50)\end{array}$ & & & -- & 0.15 & $0.36^{*}$ & 0.10 & -0.18 & 0.04 & -0.18 & -0.11 & -0.22 & 0.16 & -0.26 \\
\hline $\begin{array}{l}\text { 5. } 2012 \text { income } \\
(n=50)\end{array}$ & & & & & -- & $0.28^{*}$ & 0.04 & -0.21 & 0.04 & -0.17 & 0.07 & -0.16 & -0.23 \\
\hline $\begin{array}{l}\text { 6. Marital status } \\
(\mathrm{n}=51)\end{array}$ & & & & & & -- & 0.18 & -0.01 & 0.13 & 0.28 & 0.20 & -0.12 & -0.05 \\
\hline $\begin{array}{l}\text { 8. Weight-for-age } \\
z \text {-score }(n=48)\end{array}$ & & & & & & & & -- & $0.39^{*}$ & $0.75^{\star \star}$ & 0.29 & $-.48^{* *}$ & $0.54^{* *}$ \\
\hline $\begin{array}{l}\text { 9. Height-for-age } \\
z \text {-score }(n=37)\end{array}$ & & & & & & & & & -- & $0.33^{*}$ & $0.86^{\star *}$ & $-0.59^{* *}$ & 0.33 \\
\hline $\begin{array}{l}\text { 10. Current } \\
\text { weight }^{\mathrm{b}}(n=48)\end{array}$ & & & & & & & & & & -- & $0.58^{* *}$ & $0.35^{\star}$ & $0.44^{*}$ \\
\hline $\begin{array}{l}\text { 11. Current } \\
\text { height }^{\mathrm{c}} \\
(\mathrm{n}=46)\end{array}$ & & & & & & & & & & & -- & $-0.53^{* *}$ & 0.30 \\
\hline $\begin{array}{l}\text { 12. Body mass } \\
\text { index } z \text {-score } \\
(n=37)\end{array}$ & & & & & & & & & & & & -- & 0.30 \\
\hline
\end{tabular}

${ }^{*}$ Correlation significant at the 0.05 level (2-tailed).

${ }^{* *}$ Correlation significant at the 0.01 level (2-tailed).

${ }^{a}$ Sample sizes vary since the caregivers were given the option to omit any question if so desired.

${ }^{b}$ Currentweight of study children in kilograms.

${ }^{\circ}$ Current height of study children in centimeters.

dBirthweight of study children in kilograms. 
reflects a faster eating rate as birth weight increased in the children $(r=-0.40, P=0.04)$. Children with low birthweight $(<2.5 \mathrm{~kg})$ had higher scores in Food Responsiveness $[M=2.4, S D=0.8, \quad M=1.9, \quad S D=1.2$, respectively; $t(38)=2.609, P=0.01]$ and Food Approach $[M=3.0, \quad S D=0.8, \quad M=2.9, \quad S D=1.2, \quad$ respectively; $t(37)=2.373, P=0.02]$ than children with birthweight equal to or greater than $2.5 \mathrm{~kg}$. In addition, the children's birthweight was positively related to weightfor-age $z$-scores $(r=0.54, P=<0.01)$ and current weight $(r=0.44, P=0.02)$ but was not significantly associated with age.

The study sample means for weight-for-age $z$-score $[t(47)=1.750, \quad P=0.09], \quad$ height-for-age $\quad z$-scores $[t(44)=0.339, P=0.74]$, and BMI $z$-scores $[t(36)=0.708$, $P=0.48$ ] showed no statistical difference to U.S norms $(M=0)$, which were based on the CDC Growth Charts (2000). However, evaluation between anthropometric measurements by sex in the study children found that, in the height-for-age $z$-scores, boys were significantly shorter than the girls $[t(42.2)=-2.027, P=0.05]$. There were no significant findings between the CEBQ subscales and the weight-for-age $z$-scores, height-forage z-scores, BMI z-scores, or BMI percentile groups.

In comparison of differences in low birthweight percentages, the percentage of low birthweight in the children with FASDs was significantly differently than the U.S. 2013 percentage of low birthweight (8.0\%) $\left[X^{2}(1)=144.0, P=0.0001\right]$ [37]. When comparing normal to not normal weight percentages (combined underweight and overweight percentages), the preschool-aged study children's percentages compared to the U.S. 2011 to 2012 percentages ( $74 \%$ and $26 \%$, respectively) were significantly different $\left[X^{2}(1)=4.27\right.$, $P=0.04][39]$.

Comparisons were conducted between the children with FASDs, aged 3 to 5 years, and the normative sample of the Wardle et al. study [20]. By sex (Table 2 ), the boys with FASDs were significantly different in Emotional Overeating $(P=0.02)$, Desire to Drink $(<P=0.01)$, Food Fussiness $(P=0.03)$, Food Responsiveness $(P=0.04)$, and Enjoyment of Food $(P=0.001)$ when compared to the normative sample of boys. Girls with FASDs, compared to the girls of the normative sample, were significantly different in Desire to Drink $(P=0.03)$ and Food Responsiveness $(<P=0.01)$. When assessed by age (Table 3$)$, there was statistically significant difference in Food Fussiness ( $P=0.02, P=0.03$, respectively) between the 3 - and 5year-olds with FASDs and the 3-and 5-year-olds of the normative sample. The 4-year-old children with FASDs were significantly different from the 4-year-olds of the normative sample in Desire to Drink $(P=0.04)$ and Food Responsiveness $(P=0.01)$, while 5 -year-olds with FASDs were significantly different in Enjoyment of Food $(P=0.001)$ compared to the normative sample of 5 -year-olds. Means and standard deviations, regarding comparisons between the children with FASDs, aged 3 to 5 years, and the normative sample, are in Tables 2 and 3.

\section{DISCUSSION}

To the investigators' knowledge, this study was the first to explore the eating behavior of children with FASDs, aged 3 to 5 years, using the CEBQ in an online survey. Most notably in the study, caregivers reported the children had atypical eating behaviors of abnormal appetite, emotional overeating, selective eating, slower eating, and an excessive need for drinks. Given that young children with FASDs exhibit atypical eating behaviors, it is important to evaluate nutritional status and weight status in FASD and provide early intervention to prevent malnutrition, especially during critical times in brain development.

To identify characteristics affecting childhood nutrition and weight, the CEBQ subscales describe the eating behavior of children [20]. In this study, $6 \%$ of children were below the $5^{\text {th }}$ percentile in weight-for-age and $20 \%$ below the $5^{\text {th }}$ percentile in height-for-age. In regards to $z$-scores, there were no differences between the weight-for-age $z$-scores and height-for-age $z$ scores in the study children and the U.S. norms (based on the 2000 CDC Growth Charts) or in CEBQ subscales [32]. Even though some preschool children with FASDs may fall in normal growth patterns, habitual atypical eating behavior could affect future growth. Previous studies have found relationships between CEBQ subscales and BMI in children of typical development; however, there were no significant findings between the BMI z-scores or BMI percentile groups and the CEBQ subscale scores in the study children. This may be due to the small sample sizes or the differences in adiposity rebound in preschool children or the FASD condition itself [40].

Associations were present between the CEBQ subscales and birthweight of the study children. Since children with FASDs of higher birthweight had a faster rate of eating, eventual excessive weight gain or obesity may be a consequence from eating too quickly [20]. Equally important, the percentage of low 
birthweight children in this study was significantly different than the national rate $[14,41]$. There are implications that low birthweight and malnutrition play a role in long-term adult health consequences, such as obesity, because of alterations in epigenetic markers [42]. Results of this study found low birthweight in FASD was associated with stimulators of food intake, particularly related to a higher tendency to eat when prompted by external food cues [20]. Since low birthweight is commonly associated with prenatal alcohol exposure, the finding is suggestive that some atypical eating behaviors may be the result of epigenetic modifications from alcohol's teratogenic effects and/or maternal malnutrition.

Assessment of the CEBQ subscales and sociodemographic characteristics revealed positive and negative food intake eating behaviors in the study children. Stimulators of food intake were noted in children with FASDs, aged 3 to 5 years, who lived in larger families. One explanation may be that larger families may offer a wider range and amount of foods at meals and snack times. Another may be that some children with FASDs have sensory processing disorders causing them to either seek or avoid sensations [43]. Hence, if the children with FASDs are sensory seekers that live in larger families, the environment may be stimulating food intake. This may result in a heightened desire to eat and more external food cues, which lead to overeating and excessive weight [34]. Conversely, study children with collegeeducated caregivers had higher Food Avoidance than with high school/Vo Tech educated caregivers. One explanation may be that caregivers with higher education have more exposure to nutrition information and practice greater restraint of food intake to avert overweight/obesity [44]. Similar to the original CEBQ findings, differences were also noted by age and not by sex [20]. In the study children, Slowness in Eating was more prevalent in 3-year-olds than 5-year-olds, which was akin to the normative sample in Wardle et al. with Slowness in Eating decreasing with age [20].

The preschool-aged children with FASDs were found to have atypical behaviors in both stimulators and inhibitors of eating when compared to a normative sample. There was identification of higher Desire to Drink and Food Fussiness in study children, which may influence the diet by increasing intake of calories from sugar and limiting dietary variety $[45,46]$. A recent nutrition study reported that children with FASDs, aged 4 to 14 years, were selective eaters and had a diet high in simple sugars with deficiencies in micronutrients [13]. Consumption of sugar-sweetened beverages, such as soft drinks and fruit juices, adds excessive simple sugar to the diet and is a major public health concern because of increased risk for overweight/obesity in childhood [46, 47]. A policy statement from the American Academy of Pediatrics recommends that children, aged 1 to 6 years, have less than 6 ounces of fruit juice per day [48]. Also, animal models with selective eating ate more when fed preferred, palatable foods, which indicates selective eating or food fussiness, may not only be a risk for underweight but also for obesity [20].

The CEBQ subscales of Enjoyment of Food and Food Responsiveness define the different appetite levels in young children as general and maladaptive [20]. The regulation of appetite, an important determinant of eating behavior and weight, requires proper communication between the central nervous system (CNS) and intestinal hormones; however, this interplay in FASD may be altered due to alcohol-related abnormalities interfering with the physiology of the CNS and gastrointestinal tract $[3,49,50]$. With reduced appetite or food enjoyment, such as in study's boys and 5-year-olds with FASDs, food intake and weight may decrease. A recent study found poor appetite present in young children with prenatal alcohol exposure [13]. However, with maladaptive appetite levels cued by external sources, such as seen in the study children (boys, girls, and 4-year-olds), children may have a propensity to overeat, which would increase the risk of obesity [20]. Hence, if the dysregulation of appetite from higher Food Responsiveness and Emotional Overeating is longterm, the consequences of the excessive food intake would include overweight/obesity.

From caregiver reports, atypical eating behaviors in children with FASDs, aged 3 to 5 years, were identified that can lead to clinically significant nutritional problems and weight issues. Since the eating problems vary, as does the many other alcohol-related deficits in FASD, there is a clear need for nutrition assessment, services, and interventions specifically tailored for $\operatorname{FASD}[3,51]$. The current study findings add to the existing literature by providing formative information to encourage further investigation into the atypical eating behaviors and the types of effective interventions to manage nutrition care in children with FASDs, aged 3 to 5 years. 


\section{STRENGTH AND LIMITATIONS}

The study had limitations, which should be under consideration. The anthropometric measurements of the children with FASDs were caregiver-reported and not professionally measured but it was felt that this information was meaningful to the study due to the caregiver's concerns and efforts to respond to the survey questions. This study was cross-sectional, which does allow for evidence of associations but not for identification of causality. More importantly, a major strength was that the study received responses from caregivers of preschool-aged children with FASDs across the United States and some internationally. Another limitation was that data were from purposive sampling and self-reported responses from caregivers, which are retrospective and may lead to under- or overreporting due to social desirability. To lessen the effects of social desirability, caregivers were instructed their responses would be anonymous without any personal identifiers. Caregiver participation may also be limited because the survey was online but the snowball approach was used to increase the range of recruitment. At the same time, since the average age of FASD diagnosis is 9.5 years old (reported by the Washington State FAS Diagnostic and Prevention Network), participation may not be representative of all preschoolers with FASDs because some children may have not yet been formally diagnosed [52]. Yet, the study found that preschool-aged children with an FASD diagnosis were exhibiting a disruption in eating, indicating an early onset of atypical eating behaviors. In addition, the CEBQ subscales may not have captured all aspects of atypical eating behavior in the preschoolaged children with FASDs but, as an assessment tool, the CEBQ has been validated to identify eating behaviors in a variety of children [20]. Notably, another major strength was that the study addressed a stage in child development in which the young child is transitioning into independent eating and is a critical time for the provision of proper nutrition to brain for optimal development.

\section{CONCLUSIONS}

Atypical eating behaviors, consisting of maladaptive appetites, emotional overeating, selective eating, slower eating rates, and an increased need for drinks, were identified in children with FASDs, aged 3 to 5 years. This is of major concern since nutritional inadequacies in young children with FASDs may further impair their growth and development, which is already compromised from the effects of prenatal alcohol exposure. In light of the study findings, early nutritional assessment, services, and interventions by registered dietitian nutritionists are important for children with FASDs to prevent possible nutrition deficits and improve the eating behavior.

\section{Applications and Implications for Further Research}

With the identification of atypical eating behaviors, this supports the need for tailored nutrition intervention for children with FASDs and nutrition education for their caregivers [53]. Children with FASDs, who overeat because of emotional stress or external food cues, may require nutrition interventions helping them to express their emotions, instead of eating, and to respond to stress or environmental food intake stimulators by substituting a non-food activity, such as walking. Nutrition education can provide caregivers with information that encourages limiting fruit juice to 6 ounces/day and increasing healthier beverage choices, such as low-fat milk, to avoid sugar-sweetened drinks [54]. Also, nutrition education for caregivers can emphasize the importance of having regularly scheduled meals and snacks in a setting with limited distractions, which may address the issues of lack of enjoyment in eating and maladaptive appetites [55]. To improve food fussiness, nutrition counseling can suggest strategies to caregivers about frequently offering new food with foods favored by the children, or to blend the non-preferred food with a preferred food to improve nutrition $[55,56]$. Considering the sensory problems associated with FASD and indications of atypical eating behaviors, future investigations may focus on the relationship of sensory processing disorders and selective eating behavior in children with FASDs $[13,43]$.

\section{ACKNOWLEDGEMENTS}

The authors sincerely thank the caregivers who generously shared their time to participate in this research project.

\section{REFERENCES}

[1] Streissguth AP, Bookstein FL, Barr HM, Sampson PD, O'Malley K, Young JK. Risk factors for adverse life outcomes in fetal alcohol syndrome and fetal alcohol effects. JDBP 2004; 25(4): 228-38. https://doi.org/10.1097/00004703-200408000-00002

[2] Haycock PC. Fetal alcohol spectrum disorders: the epigenetic perspective. Biol Reprod 2009; 81(4): 607-17. https://doi.org/10.1095/biolreprod.108.074690

[3] Burd L, Martsolf JT. Fetal alcohol syndrome: diagnosis and syndromal variability. Physiol Behav 1989; 46(1): 39-43. https://doi.org/10.1016/0031-9384(89)90318-1 
[4] Clarren SK, Smith DW. The fetal alcohol syndrome. N Engl J Med 1978; 298: 1063-7. https://doi.org/10.1056/NEJM197805112981906

[5] Van Dyke DC, Mackay L, Ziaylek EN. Management of severe feeding dysfunction in children with fetal alcohol syndrome. Clin Pediatr (Phila)1982; 21(6): 336-9. https://doi.org/10.1177/000992288202100603

[6] Abel EL, Sokol RJ. Fetal alcohol syndrome is now leading cause of mental retardation. Lancet 1986; 2(8517): 1222. https://doi.org/10.1016/S0140-6736(86)92234-8

[7] Livingston J, Lyall H. Contribution of fetal alcohol syndrome to mental retardation. Lancet 1986; 2(8519): 1337-8. https://doi.org/10.1016/S0140-6736(86)91468-6

[8] Chudley AE, Conry J, Cook JL, Loock C, Rosales T, LeBlanc $\mathrm{N}$. Fetal alcohol spectrum disorder: Canadian guidelines for diagnosis. CMAJ 2005; 172(5 Suppl): S1-21. https://doi.org/10.1503/cmaj.1040302

[9] May PA, Gossage JP. Estimating the prevalence of fetal alcohol syndrome. A summary. Alcohol Res Health 2001; 25(3): 159-67.

[10] Presson AP, Partyka G, Jensen KM, Devine OJ, Rasmussen SA, McCabe LL, et al. Current estimate of down syndrome population prevalence in the United States. J Pediatr 2013; 163(4): 1163-8. https://doi.org/10.1016/j.jpeds.2013.06.013

[11] Boulet SL, Gambrell D, Shin M, Honein MA, Mathews TJ. Racial/Ethnic differences in the birth prevalence of spina bifida-United States, 1995-2005. MMWR [serial on the Internet] 2009 Jan 9 [cited on 2016 Aug 6]; 57(53): 1409-13.

[12] Spohr H-L, Willms J, Steinhausen H-C. Fetal alcohol spectrum disorders in young adulthood. J Pediatr 2007; 150(2): 175-9, 179.e1.

[13] Werts RL, Van Calcar SC, Wargowski DS, Smith SM. Inappropriate feeding behaviors and dietary intakes in children with fetal alcohol spectrum disorder or probable prenatal alcohol exposure. Alcohol Clin Exp Res 2014; 38(3): 871-8.

https://doi.org/10.1111/acer.12284

[14] Truong KD, Reifsnider OS, Mayorga ME, Spitler $H$. Estimated number of preterm births and low birth weight children born in the United States due to maternal binge drinking. Maternal Child Health J 2013; 17(4): 677-88. https://doi.org/10.1007/s10995-012-1048-1

[15] Bruns DA, Thompson SD. Feeding challenges in young children toward a best practice model. Infant Young Child 2010; 23(2): 93-102. https://doi.org/10.1097//YC.0b013e3181d5c379

[16] Uc A, Vasiliauskas E, Piccoli DA, Flores AF, Di Lorenzo C, Hyman PE. Chronic intestinal pseudoobstruction associated with fetal alcohol syndrome. Dig Dis Sci 1997; 42(6): 1163-7. https://doi.org/10.1023/A:1018833503080

[17] Kvigne VL, Leonardson GR, Borzelleca J, Neff-Smith M, Welty TK. Hospitalizations of children who have fetal alcohol syndrome or incomplete fetal alcohol syndrome. S D Med 2009; 62(3): 97, 9, 101-3.

[18] Fuglestad AJ, Fink BA, Eckerle JK, Boys CJ, Hoecker HL, Kroupina MG, et al. Inadequate intake of nutrients essential for neurodevelopment in children with fetal alcohol spectrum disorders (FASD). Neurotoxicol Teratol 2013; 39: 128-32. https://doi.org/10.1016/j.ntt.2013.06.005

[19] Rosales FJ, Reznick JS, Zeisel SH. Understanding the role of nutrition in the brain and behavioral development of toddlers and preschool children: identifying and addressing methodological barriers. Nutr Neurosc 2009; 12(5): 190-202. https://doi.org/10.1179/147683009X423454

[20] Wardle J, Guthrie CA, Sanderson S, Rapoport L. Development of the children's eating behaviour questionnaire. J Child Psychol Psychiatry 2001; 42(7): 963-70.

https://doi.org/10.1111/1469-7610.00792
[21] Braet C, O'Malley G, Weghuber D, Vania A, Erhardt É, Nowicka $\mathrm{P}$, et al. The assessment of eating behaviour in children who are obese: a psychological approach. A position paper from the European Childhood Obesity Group. Obesity Facts 2014; 7(3): 153-64.

[22] Golan M, Weizman A. Reliability and validity of the Family Eating and Activity Habits Questionnaire. Eur J Clin Nutr 1998; 52(10): 771-7. https://doi.org/10.1038/sj.ejcn.1600647

[23] Anandakrishna L, Bhargav N, Hegde A, Chandra P, Gaviappa D, Shetty A. Problematic eating and its association with early childhood caries among 46-71-month-old children using Children's Eating Behavior Questionnaire (CEBQ): a cross sectional study. Indian J Dent Res 2014; 25(5): 602-6. https://doi.org/10.4103/0970-9290.147101

[24] Steinhausen HC, Spohr HL. Long-term outcome of children with fetal alcohol syndrome: psychopathology, behavior, and intelligence. Alcohol Clin Exp Res 1998; 22(2): 334-8. https://doi.org/10.1111/j.1530-0277.1998.tb03657.x

[25] Mogharreban C, Nahikan-Nelms M. Autonomy at mealtimes: building healthy food preferences and eating behavior in young children. Early Child Educ J 1996; 24(1): 29-32. https://doi.org/10.1007/BF02430547

[26] Kvigne VL, Leonardson GR, Neff-Smith M, Brock E, Borzelleca J, Welty TK. Characteristics of children who have full or incomplete fetal alcohol syndrome. J Pediatr 2004; 145(5): 635-40. https://doi.org/10.1016/j.jpeds.2004.07.015

[27] Achenbach TM, Rescorla, LA. Manual for the ASEBA preschool forms \& profiles. Burlington, VT: University of Vermont, Research Center for Children, Youth, and Families 2000.

[28] Hogan H, Cantwell PJ, Devine J, Mule VT, Velkoff V. Quality and the 2010 census. Popul Res Policy Rev 2013; 32(5): 637-62.

https://doi.org/10.1007/s11113-013-9278-5

[29] United States ${ }^{\mathrm{TM}}$ Census 2010 Explore the form. [homepage on the Internet]. Washington, DC: United States Bureau ${ }^{\mathrm{TM}}$. [updated 2014 April 21, cited 2016 Nov 15]: Available from: http://www.census.gov/2010census/about/interactiveform.php.

[30] Hazrati S, Hourigan SK, Waller A, Yui Y, Gilchrist N, Huddleston $\mathrm{K}$, et al. Investigating the accuracy of parentally reported weights and lengths at 12 months of age as compared to measured weights and lengths in a longitudinal childhood genome study. BMJ Open [serial on the Internet]. 2016 April 8;[cited 2016 Oct 6]6:e011659.

[31] Adegboye A, Heitmann B. Accuracy and correlates of maternal recall of birthweight and gestational age. BJOG 2008; 115(7): 886-93. https://doi.org/10.1111/j.1471-0528.2008.01717.x

[32] Dean AG, Sullivan, K., Arner TG, Sangam, S., Sunki, G. Friedman, R. et al. A database and statistics program for public health professionals for use on Windows 95, 98, and NT computers. Atlanta, GA: Centers for Disease Control and Prevention; 2000.

[33] Mei Z, Grummer-Strawn LM, Pietrobelli A, Goulding A, Goran MI, Dietz WH. Validity of body mass index compared with other body-composition screening indexes for the assessment of body fatness in children and adolescents. Am J Clin Nutr 2002; 75(6): 978.

[34] Webber L, Hill, C., Saxton, J., Van Jaarsveld, CHM, Wardle, J. Eating behavior and weight in children. Int J Obesity 2009; 33(1): 1-14.

https://doi.org/10.1038/ijo.2008.219

[35] Santos JL, Ho-Urriola JA, Gonzalez A, Smalley SV, Dominguez-Vasquez $\mathrm{P}$, Cataldo $\mathrm{R}$, et al. Association between eating behavior scores and obesity in Chilean children. Nutr J [serial on the Internet] 2011 October 11; [cited 2016 Oct 9] 10(1): 108. 
[36] Grube M, Bergmann S, Keitel A, Herfurth-Majstorovic K, Wendt $\mathrm{V}$, von Klitzing $\mathrm{K}$, et al. Obese parents - obese children? Psychological-psychiatric risk factors of parental behavior and experience for the development of obesity in children aged 0-3: study protocol. BMC Public Health [serial on the Internet] 2013 February 8 [cited 2016 Oct 9]; 13(1): 1193.

[37] U.S. Department of Health and Human Services, Health Resources and Services Administration, Maternal and Child Health Bureau. Child Health USA 2014. Rockville, Maryland: U. S. Department of Health and Human Services, 2014. Available from: http://mchb.hrsa.gov/chusa14/

[38] Cohen J. Statistical power analysis for behavioral sciences (2nd ed.) [book on the Internet]. New Jersey: Lawrence Erlbaum; 1988 [cited on 2016 Aug 12]. Available from: http://www.sciencedirect.com/science/book/9780121790608.

[39] Ogden CL, Carroll MD, Brian KK, Flegal KM. Prevalence of childhood and adult obesity in the United States, 2011-2012. JAMA 2014; 311(8): 806-14. https://doi.org/10.1001/jama.2014.732

[40] Rolland-Cachera MF, Deheeger M, Bellisle F, Sempé M, Guilloud-Bataille M, Patois E. Adiposity rebound in children: a simple indicator for predicting obesity. Am J Clin Nutr 1984; 39(1): 129-35.

[41] Centers for Disease Control and Prevention National Center for Health Statistics. National Vital Statistics System. Birth Data. [homepage on the Internet] Atlanta, GA: U. S. Department of Health \& Human Services 2013 [updated on 2015 Sept 29; cited on 2016 Aug 12]. Available from: http://www.cdc.gov/nchs/births.htm.

[42] Milagro FI, Mansego ML, De Miguel C, Martinez JA. Dietary factors, epigenetic modifications and obesity outcomes: progresses and perspectives. Mol Aspects Med 2013; 34(4): 782-812. https://doi.org/10.1016/j.mam.2012.06.010

[43] Carr JL, Agnihotri S, Keightley M. Sensory processing and adaptive behavior deficits of children across the fetal alcohol spectrum disorder continuum: sensory processing and adaptive behaviors across the FASD continuum. Alcohol Clin Exp Res 2010; 34(6): 1022-32. https://doi.org/10.1111/j.1530-0277.2010.01177.x

[44] Freudenberg N, Ruglis J. Reframing school dropout as a public health issue. Preventing Chronic Disease. Centers for Disease Control and Prevention. Washington, DC: U. S. Department of Health and Human Services; 2007 4(4): A107 [updated on 2012 March 30; cited on 2016 Aug 12].
[45] Bremer AA, Lustig RH. Effects of sugar-sweetened beverages on children. Pediatr Ann 2012; 41(1): 26-30. https://doi.org/10.3928/00904481-20111209-09

[46] Nickelson J, Lawrence JC, Parton JM, Knowlden AP, McDermott RJ. What proportion of preschool-aged children consume sweetened beverages? J Sch Health 2014; 84(3): 185-94. https://doi.org/10.1111/josh.12136

[47] Gidding SS, Dennison BA, Birch LL, Daniels SR, Gilman $M W$, et al. Dietary recommendations for children and adolescents: a guide for practitioners. Pediatr 2006; 117(2): 544-59. https://doi.org/10.1542/peds.2005-2374

[48] Committee on Nutrition. American Academy of Pediatrics: The use and misuse of fruit juice in pediatrics. Pediatr 2001; 107(5): 1210-13.

https://doi.org/10.1542/peds.107.5.1210

[49] Perry B, Wang Y. Appetite regulation and weight control: the role of gut hormones. Nutr Diabetes 2012; 2(1): e26. https://doi.org/10.1038/nutd.2011.21

[50] Hofer R, Burd L. Review of published studies of kidney, liver, and gastrointestinal birth defects in fetal alcohol spectrum disorders. Birth Defects Res A Clin Mol Teratol 2009; 85(3): 179-83.

https://doi.org/10.1002/bdra.20562

[51] Olson HC, Jirikowic T, Kartin D, Astley S. Responding to the challenge of early intervention for fetal alcohol spectrum disorders. Infants Young Child 2007; 20(2): 172-89. https://doi.org/10.1097/01.IYC.0000264484.73688.4a

[52] Atkins L, Michie S. Designing interventions to change eating behaviours. Proc Nutr Soc 2015; 74(2): 164-70. https://doi.org/10.1017/S0029665115000075

[53] Rader RK, Mullen KB, Sterkel R, Strunk RC, Garbutt JM. Opportunities to reduce children's excessive consumption of calories from beverages. Clin Pediatr (Phila) 2014; 53(11): 1047-54. https://doi.org/10.1177/0009922814540989

[54] Satter E. Eating competence: definition and evidence for the Satter Eating Competence model. J Nutr Educ Behav 2007; 39(5 Suppl): S142-53. https://doi.org/10.1016/j.jneb.2007.01.006

[55] Satter E. The feeding relationship: problems and interventions. J Pediatr 1990; 117(2 Pt 2): S181-9. https://doi.org/10.1016/S0022-3476(05)80017-4 